\title{
Small bowel transplantation in children: an immunohistochemical study of intestinal grafts
}

G Fromont, N Cerf-Bensussan, N Patey, D Canioni, C Rambaud, O Goulet, D Jan, Y Révillon, C Ricour, N Brousse

\begin{abstract}
Seven children with short bowel syndrome underwent small bowel allografting. Episodes of early rejection were observed in five patients who received a graft from paediatric or adult donors but not in two patients who received a neonatal graft. This study aimed, firstly, to define immunohistochemical parameters accompanying rejection and, secondly, to compare immunohistochemical parameters in neonatal grafts with those in grafts from older donors. An immunohistochemical analysis was performed on 85 intestinal biopsy specimens taken for monitoring the transplants. Acute histological rejection was associated with pericryptic infiltrates of $\mathrm{CD} 3+\mathrm{TcR} \alpha \beta+\mathrm{T}$ cells containing clusters of CD8 + cells, numerous CD25+ cells, and increased numbers of $\mathrm{CD68+}$ macrophages. These changes were associated with the appearance of major histocompatibility (MHC) class II antigens on crypt enterocytes and with an appreciable increase in the expression of E-selectin on mucosal endothelial cells. Immunohistochemistry was useful in predicting rejection by showing the appearance of pericryptic CD25+ $T$ cells 48 hours before the first histological lesions of crypt necrosis. Comparison of neonatal grafts with grafts from older donors did not show any significant difference in the density of CD68 + macrophages or in the endothelial expression of intercellular adhesion molecule-1, vascular cell adhesion molecule-1, or E-selectin. In contrast to grafts from older donors, however, neonatal grafts did not express MHC class II antigens on epithelial cells and contained very low numbers of intraepithelial lymphocytes. These data indicate, firstly, that immunohistochemistry is useful for monitoring intestinal transplants and, secondly, that the better clinical tolerance of neonatal allografts may be related to the lower immunogenicity of the neonatal epithelium.

(Gut 1995; 37: 783-790)
\end{abstract}

Keywords: bowel allograft, paediatric, immunohistochemistry.

Small bowel transplantation is the definitive treatment for patients who have undergone extensive intestinal resection and are surviving on total parenteral nutrition. After many experimental studies and the introduction of new immunosuppressive drugs, small bowel transplantation was first performed in humans in 1985..$^{1-3}$ Cyclosporin A was the first drug used, while the clinical demonstration of the superior therapeutic efficacy of FK506 ushered in the current era of small bowel and multivisceral transplantation. ${ }^{4}$ The largest reported series describes 21 adults and 22 children, including patients who have received an isolated intestinal graft, a combined liver-small bowel graft, or multivisceral grafts. ${ }^{5}$ Seven children with short bowel syndrome have received a major histocompatibility class (MHC) incompatible small bowel allograft since 1987. In five patients, the grafts were provided by paediatric or adult donors, and in two patients by anencephalic neonates. In all patients, the distal part of the graft was left as an enterostomy for at least the first three months, allowing sequential biopsy specimens and thus close histological and immunohistochemical follow up of the graft. Despite heavy immunosuppressive treatment, including cyclosporin, episodes of early acute rejection occurred in the first five patients, leading to removal of the grafts between 23 days and 17 months after transplantation. In contrast, no episode of early acute rejection occurred in the two last children, one of which still has a functional graft five years after transplantation. ${ }^{67}$

This study aimed to provide a detailed analysis of the immunohistochemical changes accompanying histological rejection and to define immunohistological criteria useful for the prediction of rejection or to follow up treatment of rejection, or both. We have studied the numbers and phenotype of $T$ cells, the numbers of natural killer (NK) cells and macrophages, and the expression of the CD25 and HLA-DR antigens. We also examined the endothelial expression of three adhesion molecules - intracellular adhesion molecule-1 (ICAM-1), vascular cell adhesion molecule-1 (VCAM-1), and E-selectin - which are induced on endothelial cells by inflammatory cytokines and which play a key role in leukocyte migration in normal and inflammatory conditions. ${ }^{8}$ In addition, immunohistochemical parameters were compared in the two groups of children to identify possible differences which might explain their different evolution and the absence of early acute rejection in the two patients who received a neonatal intestine.

\section{Methods}

PATIENTS (TABLE I)

Small bowel transplantation was performed in 
TABLE I Description of patients

\begin{tabular}{|c|c|c|c|c|c|c|c|}
\hline & \multicolumn{5}{|l|}{ Group 1 patients } & \multicolumn{2}{|c|}{ Group 2 patients } \\
\hline & 1 & 2 & 3 & 4 & 5 & 6 & 7 \\
\hline Cause of short bowel syndrome & $\begin{array}{l}\text { Neonatal midgut } \\
\text { volvulus }\end{array}$ & $\begin{array}{l}\text { Malrotation } \\
\text { volvulus }\end{array}$ & $\begin{array}{l}\text { Bands } \\
\text { volvulus }\end{array}$ & $\begin{array}{l}\text { Apple peel } \\
\text { syndrome }\end{array}$ & $\begin{array}{l}\text { Neonatal midgut } \\
\text { volvulus }\end{array}$ & $\begin{array}{l}\text { Intestinal } \\
\text { atresia }\end{array}$ & $\begin{array}{l}\text { Neonatal midgut } \\
\text { volvulus }\end{array}$ \\
\hline Age at time of transplantation & 35 mth & $6 y$ & $9 \mathrm{y}$ & $11 \mathrm{mth}$ & 9 mth & $4 \mathrm{y}$ & $5 \mathrm{mth}$ \\
\hline $\begin{array}{l}\text { Age of donor } \\
\text { Graft duration }\end{array}$ & $\begin{array}{l}12 \mathrm{y} \\
2 \mathrm{mth}\end{array}$ & $\begin{array}{l}18 \mathrm{y} \\
17 \mathrm{mth}\end{array}$ & $\begin{array}{l}17 \mathrm{y} \\
6 \mathrm{mth}\end{array}$ & $\begin{array}{l}5 \mathrm{y} \\
43 \mathrm{~d}\end{array}$ & $\begin{array}{l}5 \mathrm{y} \\
23 \mathrm{~d}\end{array}$ & $\begin{array}{l}\text { Neonate } \\
7 \mathrm{mth}\end{array}$ & Neonate \\
\hline Cause of graft removal & $\begin{array}{l}\text { Infections (CMV, } \\
\quad \text { Pneumocystis } \\
\text { carinii, EBV) } \\
\text { rejection }\end{array}$ & $\begin{array}{l}\text { Chronic } \\
\text { rejection }\end{array}$ & $\begin{array}{l}\text { Liver and } \\
\text { renal } \\
\text { failure }^{\star}\end{array}$ & $\begin{array}{l}\text { Uncontrolled } \\
\text { rejection } \\
\text { graft } \\
\text { bleeding }\end{array}$ & $\begin{array}{l}\text { Uncontrolled } \\
\text { rejection }\end{array}$ & $\begin{array}{l}\text { Uncontrolled } \\
\text { subacute } \\
\text { rejection }\end{array}$ & $t$ \\
\hline
\end{tabular}

^Responsible for death. + After six years, the intestinal graft is fully functional allowing normal feeding of the child. $\mathrm{CMV}=$ cytomegalovirus; EBV=Epstein-Barr virus.

seven children aged 5 months to 9 years, who had undergone extensive intestinal resection during the neonatal period $(n=5)$ or at 5 and 3 years of age respectively (patients 2 and 3 ) and were consequently entirely dependent on total parenteral nutrition. After approval from an ethical committee, the intestinal grafts were obtained from five donors aged 5 to 18 years (group $1=5$ patients), or from anencephalic neonates (group $2=2$ patients). All donors were HLA-mismatched to the recipient. $A B O$ groups were fully identical except in one case (patient 5), which was compatible (recipient A donor $\mathrm{O}$ ).

Procedures for harvesting the intestinal graft and for transplantation have been described elsewhere. ${ }^{7}$ To ensure a close follow up of the graft, the lower segment of the graft was left in enterostomy and only the upper extremity of the graft was anastomosed to the recipient duodenum.

Postoperative immunosuppressive treatment included methylprednisone $2 \mathrm{mg} / \mathrm{kg} / \mathrm{d}$; intravenous cyclosporine $\mathrm{A}$ to obtain a whole blood concentration of $500-600 \mathrm{ng} / \mathrm{ml}$; antilymphoglobulin (ALG) for 15 days (except in patient 2) $5 \mathrm{mg} / \mathrm{kg} / \mathrm{d}(\mathrm{n}=5)$ or $1 \mathrm{mg} / \mathrm{kg} / \mathrm{d}$ (patient 3); and azathioprine $1.5 \mathrm{mg} / \mathrm{kg} / \mathrm{d}$ from the 6th day (except in patients 2 and 3 ). In addition, all patients were left on total parenteral nutrition and received an oral mixture of antibiotics to ensure digestive decontamination of the graft. ${ }^{7}$

\section{Postoperative course (table I)}

In all cases, intestinal transit recovered within 8 hours to 6 days. Intestinal allografts were biopsied through the ileal enterostomy every two days during the first two weeks, then depending on the patient's post-transplantation course. In patient 1 , acute rejection occurred during the second month, leading to graft removal because of severe concomitant infections. In patients $2,3,4$, and 5 acute rejection was observed within the 16 days of transplantation. In children 2 and 3, treatment with ALG allowed mucosal recovery. In patient 2 , a second episode of acute rejection occurred on day 151: this failed to respond to ALG but was controlled by anti-OKT 3 monoclonal antibody $(0.1 \mathrm{mg} / \mathrm{kg} / \mathrm{d}$ for 10 days $)$. The late course after transplantation was marked by progressive, chronic rejection and the graft was therefore removed 17 months after transplantation. In patient 3 , cyclosporine was stopped on day 145 because of renal insufficiency, resulting in a second episode of rejection on day 156 . Rejection was controlled by resuming cyclosporine but the patient's general condition progressively deteriorated and she died during the 7th month because of general visceral failure. In patients 4 and 5, histological impairment and graft bleeding occurred in spite of OKT3 treatment and led to graft removal on days 43 and 23 respectively.

In patients 6 and 7, early rejection was not observed. Enteral feeding was restarted on days 30 and 20 respectively. In patient 6 , rejection episodes started only at the beginning of the 5th month, a few days after intestinal continuity was re-established; these were poorly controlled by immunosuppressive therapy and led to graft removal 7 months after transplantation. In patient 7 , four mild episodes of delayed acute rejection occurred between 3 and 19 months (days 82, 123, 220; 19th month). All episodes were controlled by the immunosuppressive treatment (respectively OKT3, anti-interleukin 2 receptor (anti-rIL2), ALG). Digestive continuity could be reestablished 8 months after transplantation. Since the 26th month after transplantation, the child has been fed entirely orally. ${ }^{7}$ Six years after grafting, she receives cyclosporine A, azathioprine $(1 \mathrm{mg} / \mathrm{kg} / \mathrm{d}$ of each), and corticosteroids $(0.5 \mathrm{mg} / \mathrm{kg}$ every two days). She is fed entirely orally, has a histologically normal graft and a normal growth curve.

\section{TISSUE SAMPLING}

Eighty five sequential graft biopsy specimens (7 to 17 per patient), taken from day 0 just after the transplantation procedure to year 2 (patient 7) were examined. Graft biopsy specimens were taken 2 to $5 \mathrm{~cm}$ above the graft stoma by using $\mathrm{H}$ Noblett forceps or within the first $\mathrm{cm}$ of the proximal graft end by using upper gastrointestinal endoscopy (Olympus, GIF-XP-10). The intestinal allografts were biopsied initially every two days, then once a month or more frequently according to clinical indications or depending on the results of the previous biopsies. Two to 3 samples were taken at one time: one sample was fixed and processed for routine histology, one or two samples were snap-frozen for immunohistochemical studies.

\section{HISTOLOGY}

Acute histological rejection was graded using four criteria: crypt necrosis, mononuclear 
TABLE II Histological scoring of acute histological rejection ${ }^{\star}$

\begin{tabular}{|c|c|c|c|c|}
\hline \multirow{2}{*}{$\begin{array}{l}\text { Histological parameters } \\
\text { of rejection }\end{array}$} & \multicolumn{4}{|c|}{ Scores for each parameter } \\
\hline & 0 & 1 & 2 & 3 \\
\hline Crypt necrosis & None & 1 or 2 crypts & $\geqslant 3$ crypts & $\begin{array}{l}\geqslant 10 \text { crypts or } \\
\text { extensive }\end{array}$ \\
\hline $\begin{array}{l}\text { Villus atrophy } \\
\text { Mononuclear cells in lamina } \\
\text { propria }\end{array}$ & $\begin{array}{l}\text { None } \\
\text { Normal density }\end{array}$ & $\begin{array}{l}\text { Focal and/or partial } \\
\text { Focal pericryptic } \\
\text { infiltrate }\end{array}$ & $\begin{array}{l}\text { Severe/total } \\
\text { Diffuse pericryptic } \\
\text { infiltrate }\end{array}$ & Diffuse infiltration \\
\hline Neutrophils/eosinophils & None or rare & $\begin{array}{l}\text { Some around or inside } \\
\text { damaged crypts }\end{array}$ & Numerous & \\
\hline
\end{tabular}

ॠHistological score was the sum of the scores obtained for each parameter in the biopsy specimens studied.

cell infiltration in the lamina propria, villous atrophy, and neutrophil or eosinophil polymorphs, as indicated in Table II. Histological scores of 2-4 were considered as mild rejection (R1); scores of 5-6 indicated moderate rejection (R2), and scores of 7-10 severe rejection (R3) (Figs 1 and 2).

Chronic rejection, observed in a single case (patient 2), was characterised by total villous atrophy and mucosal atrophy. In contrast with acute rejection, there was no crypt necrosis: crypts were short but contained numerous mitoses. In addition, there was severe endarteritis of submucosal vessels and extensive fibrosis leading to a massive shortening of the graft. The epithelium and lamina propria were infiltrated by mononuclear cells.

\section{IMMUNOHISTOCHEMISTRY}

An indirect immunoperoxidase technique previously described ${ }^{9}$ was used to stain frozen tissue sections with monoclonal antibodies directed against: $T$ cells (CD3, CD4, CD8) (leu4, leu3a, leu2a, from Becton Dickinson), macrophages (CD68) (Ki-M7 from BehringWerke AG, Marburg, Germany), NK cells (CD56), and activation markers (CD25, HLA-DR) (from Becton Dickinson, Mountainview, CA, USA). In addition, biopsy specimens were stained with an anti-TCR $\alpha \beta$ and anti-TCR $\gamma \delta$ antibodies $(\beta F 1$, and TCR $\delta 1$ respectively, T Cell Sciences, Cambridge, MA, USA) and 30 biopsy specimens were stained with antibodies against adhesion molecules ICAM-1 (E1/6, RR1), VCAM-1 (E1/7), and E-selectin (H4/18). Antibodies E1/6, E1/7, and $\mathrm{H} 5 / 18$ were a gift from Dr M P Bevilacqua (Department of Pathology, Brigham and Women's Hospital, Boston). Antibody RR1 belonged to the panel of antibodies tested for the Fifth Leukocyte Differentiation Workshop.

Quantitative or semiquantitative evaluation of each slide was performed by two independent observers (GF; NP). Numbers of labelled intraepithelial lymphocytes (IEL) in the surface epithelium were recorded as mean numbers per 100 epithelial cells, 300 to 1000 enterocytes being counted for each antibody. Numbers of labelled IEL in the crypt epithelium were expressed as mean numbers of positive cells per crypt, 10 to 50 crypts being examined. The density of labelled CD3 lamina propria lymphocytes (LPL) was evaluated semiquantitatively: $1=$ rare scattered cells; $2=$ minimal and/or focal infiltrates; $3=$ multifocal infiltrates; $4=$ diffuse infiltrate. CD25, CD56, and CD68 positive cells were recorded as absent, rare, or numerous. HLA-DR expression on villous and crypt enterocytes was noted as absent, focal, or diffuse. Positive immunostaining for adhesion molecules on mucosal

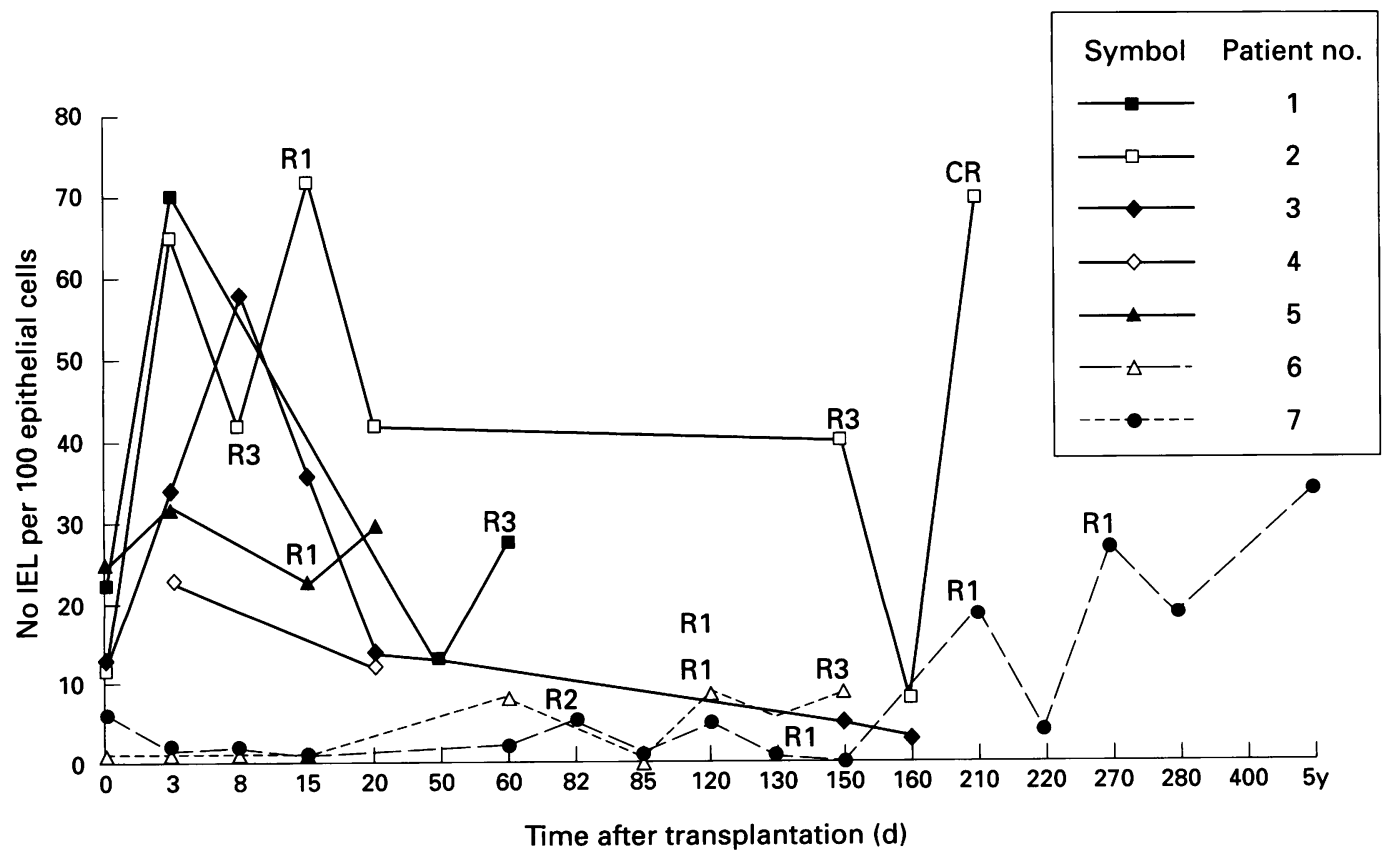

Figure 1: Comparison of the changes in the numbers of intraepithelial CD3+ lymphocytes in the seven human intestinal allografts according to time and histological rejection grading (R1 to $R 3)$. CR=chronic rejection. 


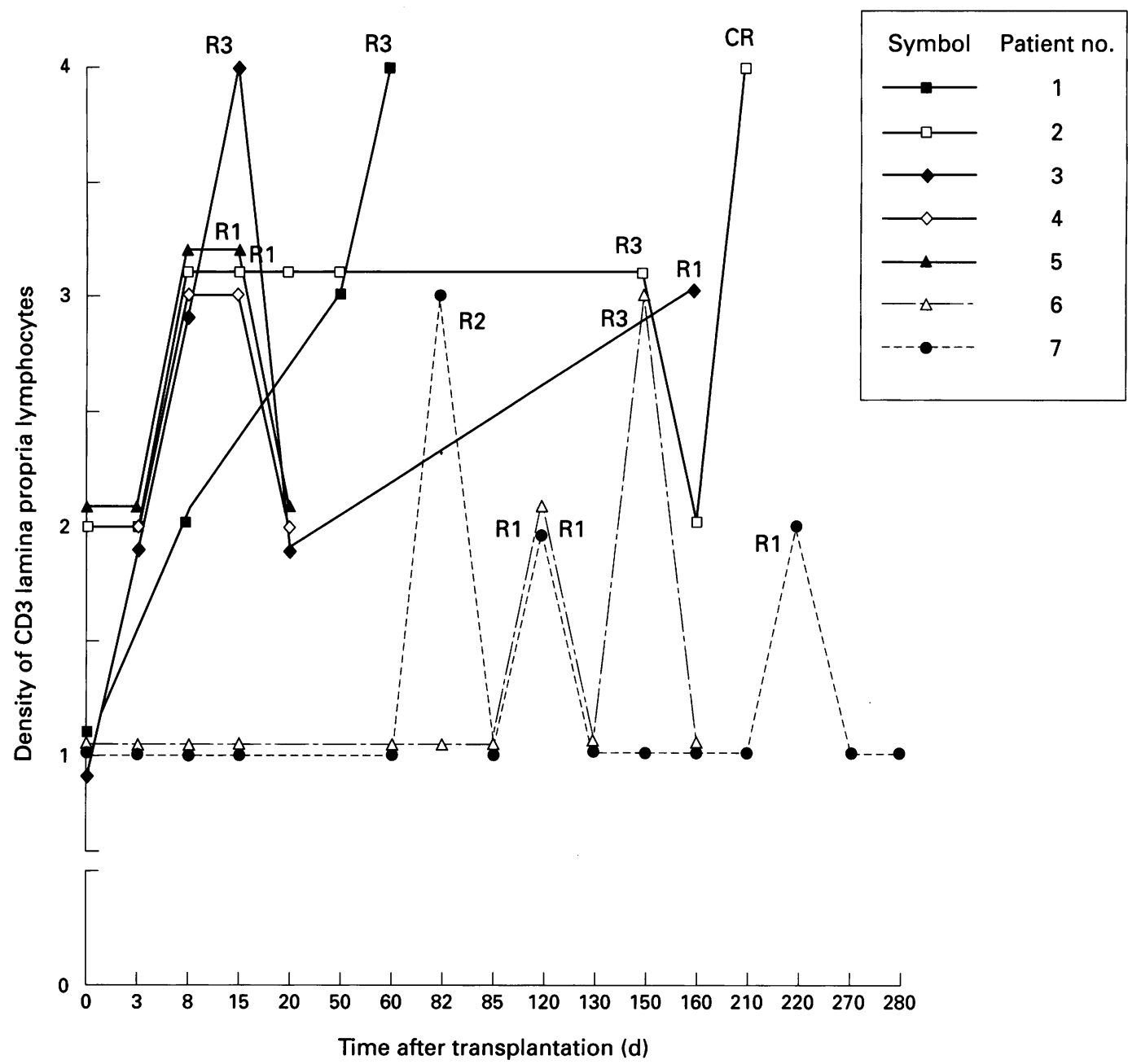

Figure 2: Comparison of the changes in the density of $C D 3+$ lamina propria lymphocytes in the seven human intestinal allografts according to time and histological rejection grading $(R 1$ to $R 3)$. CR=chronic rejection. The density of labelled CD3 lamina propria lymphocytes (LPL) was evaluated semiquantitatively: 1: rare scattered cells; 2: minimal and/or focal infiltrates; 3: multifocal infiltrates; 4: diffuse infiltrate.

vessels was expressed as: $0=$ absent; $1=$ weak (less than 3 positive vessels on a specimen); $2=$ moderate (foci of stained vessels); and $3=$ strong (numerous positive vessels).

\section{Results}

FLUCTUATIONS IN THE COUNTS OF IEL DID NOT CORRELATE WITH REJECTION (FIG 1) On day 0 , counts of CD3 + IEL in the surface epithelium were between 12 and $25 \%$ in the five patients with a graft from paediatric or adult donors (group 1; fig 1) and were therefore comparable to those observed in normal, age matched controls. ${ }^{10}$ In contrast, only $1 \%$ and $6 \% \mathrm{CD} 3+$ IEL were found in patients 6 and 7 (group 2) who had received a neonatal intestine (fig 1). During the first few days after transplantation, numbers of IEL increased in all patients in group 1 , reaching $70 \%$ in patient 1 on day 7 in the absence of any histological sign of rejection (fig 1). In contrast, in group 2, IEL counts remained very low for a considerable period of time: they increased only on day 60 in patient 6 , two weeks after enteral feeding was resumed and bowel decontamination stopped, and on day 82 in patient 7 , contemporaneously to the first episode of rejection.
Episodes of acute rejection were inconstantly associated with an increase in the numbers of IEL (fig 1). The changes in the IEL counts did not correlate with the grade of rejection. Furthermore, low IEL counts were observed in several episodes of delayed rejection occurring after day 60 . In contrast, in the single case of chronic rejection (patient 2), IEL counts were extremely high $(70 \%)$.

IEL counts varied according to the treatment: they decreased when treatment of rejection was successful (patients 2,3 , and 7) and were not modified when treatment was unsuccessful (patient 5).

IEL counts also increased during cytomegalovirus (CMV) infection: counts climbed from $20 \%$ to $30 \%$ on day 32 in patient 1 (when CMV could be detected in the blood) and from $42 \%$ to $62 \%$ on day 39 in patient 2 (when CMV inclusions could be detected on paraffin embedded intestinal sections).

IEL counts in the crypts varied between $0 \cdot 1$ and 6 per crypt and followed the fluctuations of the numbers of IEL in the surface epithelium (data not shown). The phenotype of IEL remained the same in all patients and regardless of biopsy timing: CD $3+\mathrm{TCR} \alpha \beta+$, mainly $\mathrm{CD} 8+$. No significant increase in the proportion of TCR $\gamma \delta+$ cells was observed during episodes of acute rejection. No CD25+ IEL 


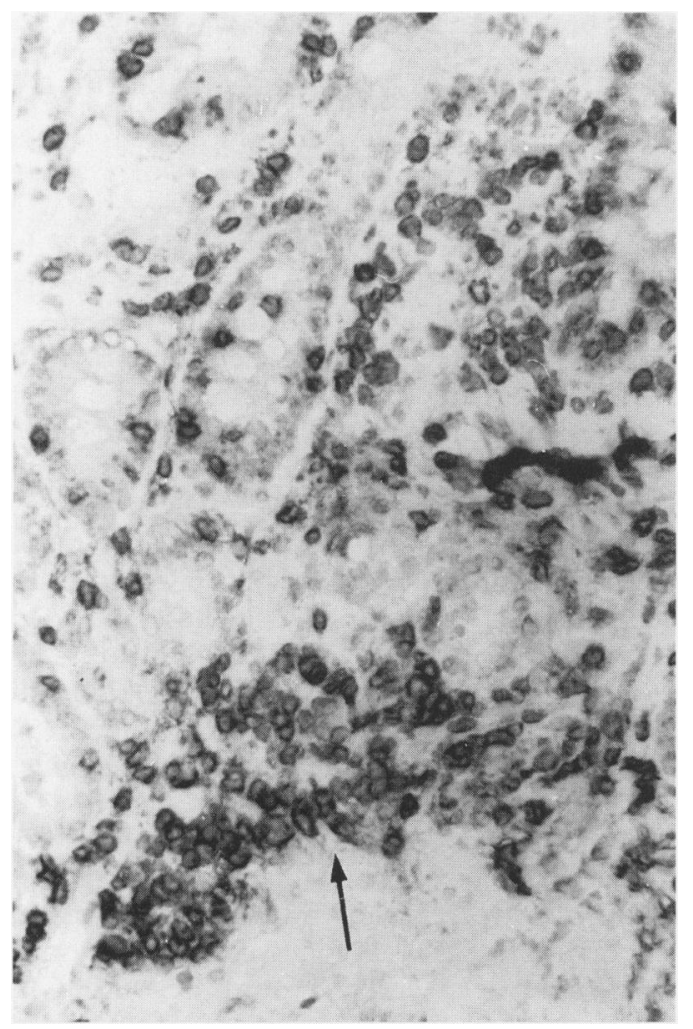

Figure 3: Early immunohistochemical changes suggestive of human intestinal graft acute rejection appearing on day 30 before histological lesions (patient 1): a cluster of CD3+ lymphocytes is visible beneath the crypts $(\rightarrow)$.

were detected, even during rejection or CMV infection.

\section{REJECTION WAS ASSOCIATED WITH}

INFILTRATION OF THE PERICRYPTIC LAMINA PROPRIA BY ACTIVATED T CELLS (FIG 2)

In group 1 patients on day $0, \mathrm{CD} 3+$ TCR $\alpha \beta+$ LPL (mainly CD $4+$, CD25-) predominated in the villous lamina propria and were rare, scattered, or in small clusters around
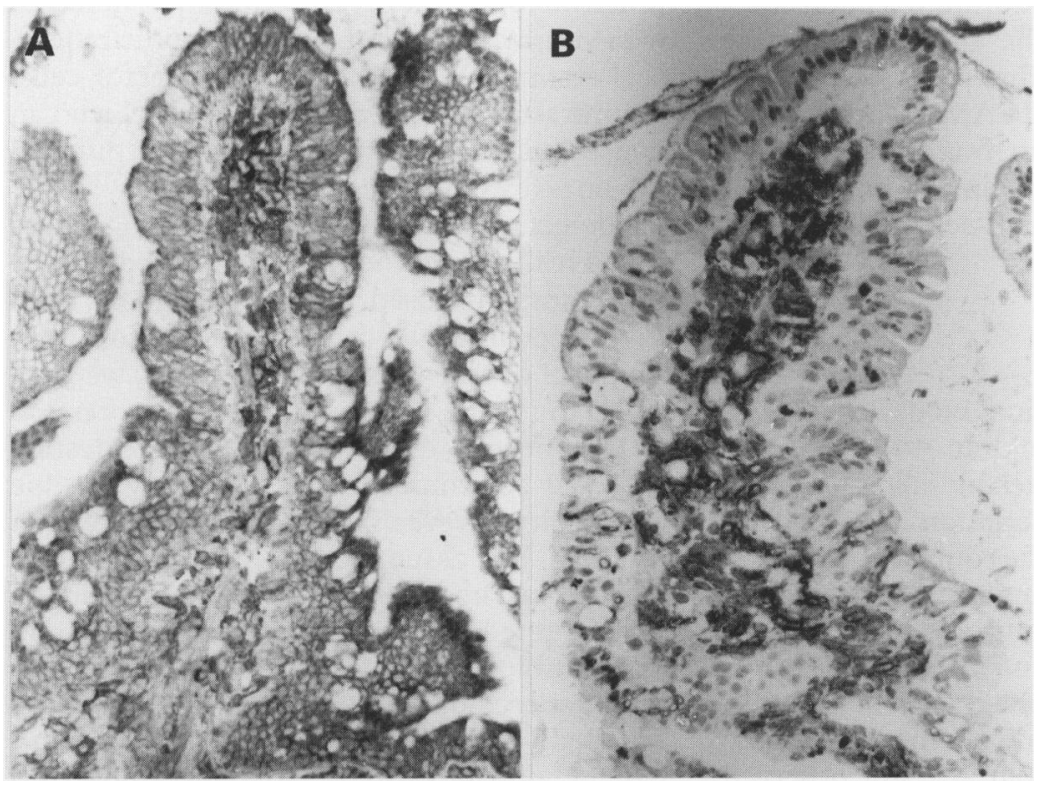

Figure 4: Small bowel transplantation: surgical specimen on day 0: immunohistochemistry with an anti-HLA-DR antibody. Diffuse expression of $H L A-D R$ antigens on villous epithelium (patient 1) (4A); no expression of $H L A-D R$ antigens on villous epithelium (patient 7) (4B). the crypts. In group 2, CD3 +LPL were rare and scattered.

During the first days after transplantation, the numbers of LPL remained moderate in group 1, and no change was observed in group 2. No foci of CD8 cells were present on biopsy specimens taken at times unrelated to a rejection episode; CD25 + cells were rare and were detected only within lymphoid follicles.

Biopsies performed 1 to 5 days before acute histological rejection $(n=5)$ were characterised by the appearance of focal pericryptic infiltrates (fig 3). These pericryptic infiltrates were mainly composed of CD3 + TCR $\alpha \beta+$ lymphocytes, and contained a high proportion of CD8 + cells (at least $50 \%$ ). Numerous cells expressing CD25 (rIL2 receptor) were observed in the 3 samples taken two days before histological rejection in the pericryptic area. In the other samples, CD25+ cells remained scarce.

During episodes of acute rejection $(n=13)$, the lamina propria contained multifocal $(n=4)$ or diffuse $(n=3) C D 3+T C R \alpha \beta+$ infiltrates in group 1 patients, and focal $(n=4)$ to multifocal $(n=2)$ infiltrates which predominated around the crypts in group 2. Foci of CD8+ cells surrounding damaged crypts were observed in 11 biopsy specimens, and numerous cells expressing CD25 were present in nine samples beneath and around the crypts. With successful treatment of rejection, the numbers of LPL decreased in all cases, with disappearance of both CD25+ cells and of CD8+ foci.

The single case of chronic rejection was associated with a diffuse infiltration of the lamina propria by $\mathrm{CD} 3+\mathrm{TCR} \alpha \beta+$ cells, many of them CD8+ cells. CD25+ cells were numerous and distributed evenly in the mucosa.

As could be expected, however, an increase in the density of lamina propria $T$ cells was not restricted to rejection but was also observed in biopsy specimens taken in two patients with evidence of continuing $\mathrm{CMV}$ infection. As during rejection, the lamina propria infiltrate contained both CD4+ and CD8+ cells. No $\mathrm{CD} 25+$ cells were observed but the frozen tissue sections examined did not contain any viral inclusions.

\section{NON-SPECIFIC EFFECTOR CELLS}

On day 0, CD68 + HLA-DR + macrophages were present in both groups of patients; they were distributed both in villous and pericryptic lamina propria. Their density increased around damaged crypts during rejection. NK cells, as revealed by the CD56 marker, were never observed, during rejection.

INCREASED HLA-DR EXPRESSION ON CRYPT EPITHELIAL CELLS DURING REJECTION HLA-DR expression at day 0 in group 1 patients was diffuse on the villous epithelium and focal on the crypts (Fig 4A). In contrast, in the two group 2 patients, HLA-DR antigens were not detected on either surface or crypt epithelium (Fig 4B). In patient 6, diffuse expression of HLA-DR by villous epithelial 
cells was first observed on day 66 . In patient 7 , HLA-DR expression was detected on the villous epithelium after day 46 but remained focal until the first episode of rejection on day 82 .

During rejection, strong HLA-DR expression was observed on the crypt epithelium. It was diffuse, involving all crypts, in the first group of patients; in the second group, HLADR expression remained focal and predominated on crypts surrounded by a mononuclear infiltrate. HLA-DR expression disappeared on the crypt epithelium with successful treatment of rejection. It persisted in patient 5 when rejection did not subside. Finally, strong, diffuse expression of HLA-DR antigens was observed on both surface and crypt epithelia in patient 2 in all biopsy specimens taken during chronic rejection.

INCREASED EXPRESSION OF E-SELECTIN ON LAMINA PROPRIA VASCULAR ENDOTHELIUM DURING REJECTION

ICAM-1 was strongly expressed at day 0 , on many deep and superficial mucosal vessels in all patients. Weak to moderate VCAM-1 expression was observed on some deep and superficial mucosal vessels in patients 2,6 , and 7: no VCAM-1 expression was detected in the other grafts. Occasional vessels expressing E-selectin were found in the deep mucosa in all patients, with a staining score of 1 .

After day 0, expression of ICAM-1 remained strong on most vessels and no significant change could be detected during rejection. Surprisingly, VCAM-1 was either absent or detected only on rare vessels, even during rejection. In contrast, during rejection, E-selectin appeared on vessels in the superficial lamina propria and the staining scores for E-selectin increased from 1 to $2-3$ in all patients. With successful treatment of rejection, E-selectin staining scores decreased from 2-3 to 1 , and labelling of superficial vessels disappeared. Although changes in E-selectin expression were evident during rejection, they were not detected in the biopsy specimens performed a few days before rejection.

It is worth noting that ICAM-1 and VCAM1 were expressed on numerous lamina propria large cells in all biopsy specimens. In contrast, ICAM-1, VCAM-1, and E-selectin were not detected on epithelial cells.

\section{Discussion}

The analysis of 85 intestinal biopsy specimens performed in seven children to follow up intestinal MHC-mismatched allografts has allowed the precise description of immunohistochemical changes accompanying acute intestinal rejection in humans. One constant immunohistochemical feature was the presence of pericryptic infiltrates of CD $3+\mathrm{TCR} \alpha \beta+\mathrm{T}$ cells and CD68+ macrophages. The clusters of CD8 + lymphocytes and of small or large CD25+ cells in these infiltrates, not observed in normal intestine, were particularly characteristic of rejection. In contrast with a mouse model of fetal intestinal allograft rejection, ${ }^{11}$ there was only an inconstant increase in the number of IEL. Moreover, IEL counts remained at a low level in 4 of 7 cases of delayed acute rejection. The constant presence of clusters of CD8 + cells around and inside necrotic crypts suggests that the latter cells are cytotoxic $T$ cells and play an important role in the epithelial destruction characteristic of intestinal rejection, a hypothesis supported by the detection of mRNA encoding for serine esterase B in the pericryptic areas of an intestinal graft undergoing acute rejection. ${ }^{12}$ In the late phases of intestinal rejection, $T$ cell infiltration involved the whole mucosa and was associated with massive recruitment of nonspecific effector cells which outnumbered $T$ cells. These included activated macrophages (CD68+, DR+, CD25+) and polymorphonuclear cells but no NK cells, at least as detected by the CD56 marker. These observations are in keeping with studies of rejected renal allografts. ${ }^{13}$ They are also comparable to the observations made in a rat model in which acute rejection of an intestinal allograft was first associated with a significant increase in the number of lamina propria $T C R \alpha \beta+C D 8 \alpha+C D 8 \alpha \beta+$ lymphocytes of recipient origin and secondarily with a strong infiltration by macrophages and polymorphonuclear cells. ${ }^{14}$

In the present study, chronic rejection was observed only once. It differed markedly from both early or delayed acute rejection. As in chronic rejection processes affecting other organs, there was a severe endarteritis and extensive fibrosis. In contrast to acute rejection, there was striking villous atrophy and even mucosal atrophy but no crypt necrosis. Infiltration by CD8 $+\mathrm{T}$ cells was diffuse and the number of IEL extremely high.

During rejection, the appearance of pericryptic activated $T$ cells was always associated with increased expression of HLA-DR antigens on crypt enterocytes. This enhanced expression is likely to be due to the production by activated T cells of $\gamma$ interferon, as detected by in situ hybridisation. ${ }^{12}$ It may contribute to local restimulation of allogeneic effector cells. In contrast, expression of ICAM-1, which can be upregulated in vitro on intestinal epithelial cell lines by inflammatory cytokines ${ }^{15} 16$ was not detected on epithelial cells during rejection. This finding does not seem to be related to the antibody used. Indeed using the Fifth Workshop on Leucocyte Differentiation antigen panel of anti-ICAM-1 antibodies, we have failed to show in situ ICAM-1 expression by enterocytes, even in inflammed intestine (personal communication). This may be due to difficulty in revealing enterocytic expression of ICAM-1 in tissue sections. Thus, in murine graft versus host disease, ICAM-1 could be demonstrated by immunofluorescence and northern blot in isolated crypt cells but not by immunoperoxidase staining in situ (D GuyGrand, P Vassalli, personal communication).

In a previous study we have observed enhanced production of IL 1 , tumour necrosis factor, and $\gamma$ interferon during intestinal allograft rejection. ${ }^{12}$ These cytokines are able to 
induce endothelial expression of ICAM-1 and VCAM-1, two adhesion molecules which are thought to play a key role in the recruitment of leukocytes to inflammatory tissues by binding their relevant receptors, the leukocyte integrins LFA-1 and VLA-4 respectively. ${ }^{8}$ In contrast with previous observations in cardiac $^{17}$ and renal $^{18}$ allografts, we were unable to show an increase in the endothelial expression of ICAM-1 during rejection. As previously observed by others, however, in colonic and ileal biopsy specimens, ${ }^{19} 20$ ICAM-1 was strongly expressed on most lamina propria capillaries on day 0 . It may therefore be difficult to show any further increase during rejection. This result is in keeping with that obtained in inflammatory bowel disease. ${ }^{20}$ On day 0 , VCAM-1 was present on endothelial cells in only three biopsy specimens, a result consistent with the observations of Koizumi et al, who observed inconstant endothelial expression of VCAM-1 in normal colonic biopsies. $^{21}$ The subsequent disappearance of VCAM-1 in these three intestinal grafts may be due to the disappearance of antigenic intraluminal stimuli (all grafts were decontaminated and patients were on exclusive parenteral nutrition) or to the immunosuppressive treatment, or both. However, no significant induction of VCAM-1 expression could be detected after enteral feeding was resumed or, more strikingly, during rejection. A comparable negative finding was made in active inflammatory bowel disease. ${ }^{21}$ Altogether these results suggest that VCAM-1 plays a minor role in leukocyte migration into either normal or inflammatory intestinal mucosa. In contrast with the lack of changes in the expression of ICAM-1 and VCAM-1, there was a clear cut induction of E-selectin at the time of rejection. Indeed, on day 0, expression of E-selectin was weak and restricted to certain blood vessels in the deepest part of the mucosa. During rejection, it increased appreciably on positive capillaries and appeared on capillaries in the superficial mucosa. In addition, it disappeared with treatment. Increased expression of E-selectin has also been found in association with inflammation in inflammatory bowel disease $^{21}$ and in renal graft rejection. ${ }^{18}$ These results emphasise the possible role of $\mathrm{E}$ selectin in leukocyte migration in inflammatory intestine, including rejected intestinal grafts, and suggest that it may be useful to investigate the effect of anti-E-selectin antibodies in the treatment of intestinal rejection.

Taken together, our findings emphasise the usefulness of immunohistochemical studies for the monitoring of intestinal allografts. In the five cases where it could be studied, the first sign of histological rejection, crypt necrosis, was preceded by the appearance of pericryptic $\mathrm{T}$ cell infiltrates containing CD8 + cells and, in three cases, by a large number of CD25 + cells, as well as by the induction of MHC class II antigens on the infiltrated crypts. In a previous study, it was suggested that the appearance of macrophages in the submucosa is a good indicator of continuing rejection. ${ }^{3}$ However, in our patients, the biopsies were superficial in order to avoid any risk of perforation and the submucosa was not visible, thus preventing assessment of the presence of submucosal macrophages. Immunohistochemistry was also useful for monitoring rejection treatment. Indeed, histological improvement is slow and can take several weeks when destruction has been extensive. In contrast, in cases where rejection treatment was successful, immunohistochemistry showed a marked decrease in the number of lamina propria $T$ cells and the disappearance of pericryptic foci of $\mathrm{CD} 8+$ cells within two days and the disappearance of HLA-DR expression on crypts and of E-selectin on superficial vessels within a week. This immunohistochemical improvement was not observed in cases of uncontrolled rejection.

Finally, the most intriguing observation was the different evolution of grafts provided by neonatal and older donors. The difference could not be easily ascribed to the treatment, which was comparable in most patients. The young age of the recipients may have contributed to better graft tolerance. Alternatively, it is possible that the neonatal intestine is less immunogenic. However, the density of CD68+ macrophages, capable of presenting donor antigens to recipient $T$ cells, was comparable in the lamina propria of neonates and of older donors. Nor was there a significant difference in the endothelial expression of three of the adhesion molecules able to recruit recipient leukocytes and thus to favour sensitisation of recipient leukocytes to donor antigens. A lesser immunogenicity of the neonatal allografts may be related to a distinctive expression of other adhesion molecules not tested in this study, such as the B7 molecules which participate in the induction of the immune response $\mathrm{s}^{22}$ or the mucosal adressin which is involved in lymphocyte homing in intestinal mucosa. ${ }^{23}$ It may also be related to a distinct immunogenicity of the epithelium. Indeed, the main differences between neonatal intestines and intestines provided by older donors were the lower numbers of IELs and the lack of expression of MHC class II antigens by epithelial cells. Such findings could be expected. In humans, it has been shown that fetal small intestine contains very few IEL $^{24}$ and does not express MHC class II antigens on epithelial cells. ${ }^{25}$ In rodents, migration of lymphocytes into the intestinal mucosa is partly dependent on the presence of intraluminal antigens which stimulate the proliferation of precursors in Peyers' patches. ${ }^{25-27}$ In young rats, expression of MHC-class II by enterocytes appears after weaning, simultaneously to the migration of IEL. ${ }^{28}$ Similarly, in the two neonatal grafts, HLA-DR expression appeared on surface epithelium following the introduction of intraluminal antigens after day 30 and was associated in one case (patient 6) with enhanced IEL counts $(20 \%)$. In the present state of knowledge, it is difficult to establish a direct relationship between the absence of epithelial HLA-DR expression, the low IEL counts, and the delay in graft rejection in group 2 . It is striking, however, that in all group 1 patients there was an early and marked 
increase in the numbers of IELs, which was not observed in the two neonatal grafts. This increase was not related to intraluminal antigenic content since all patients were on total parenteral nutrition and grafts were efficiently decontaminated. It is therefore tempting to suggest that the human intestinal epithelium acquires the ability to stimulate either expansion or migration of lymphocytes with a delay after birth. This property may reflect its immunogenicity. In vitro experiments have shown that MHC-class II+ enterocytes can present certain soluble antigens to lymphocytes $^{29-32}$ and may stimulate allogeneic intraepithelial lymphocytes. ${ }^{33}$ Interestingly, recent data suggest that the intestinal epithelium has a role in the induction of allograft rejection in rats. ${ }^{34} \mathrm{~A}$ better definition of the adhesion molecules expressed by the intestinal epithelium, as well as in vitro and in vivo studies of the immunogenicity of the intestinal epithelium, may help to explain the different evolution of grafts from neonatal and older donors. It may also help to design new therapeutical approaches.

Presented at the Third International Symposium on Small Bowel Transplantation, 3-6 November 1993, Paris, France. This work was supported by grants from Assistance Publique-Hôpitaux de Paris (AP-HP contract no 90 0106) and Société Nationale Française de Gastroentérologie.

We thank Martine Grimal for secretarial assistance, to JeanPaul Monnet for assistance with photography and to Odile Le Pelletier for performing the immunoperoxidase staining. We wish to thank Dr Elisabeth MacIntyre for the revision of the manuscript.

1 Cohen Z, Silverman RE, Wassez SG. Small intestinal transplantation using cyclosporine. Report of one case. Transplantation 1986; 42: 613-21.

2 Grant D, Wall W, Zhong R, Ghent C, Garcia B, Stiller C, Duff J. Successful small bowel-liver transplantation. Lancet 1990; 335: 181-4.

3 Asfar S, Zhong R, Grant D. Small bowel transplantation. Surg Clin North Am 1994; 74: 1197-210.

4 Tzakis AG, Todo S, Starzl TE. Intestinal transplantation. Annu Rev Med 1994; 45: 79-91.

5 Abu-Elmagd K, Todo S, Tzakis A, Reyes J, Nour B, Furukawa $\mathrm{H}$, et al. Three years clinical experience with intestinal transplantation. $\mathcal{f} \mathrm{Am}$ Coll Surg 1994; 179: intestinal

6 Goulet O, Révillon Y, Jan D, Brousse N, de Potter S, CerfBensussan N, et al. Small-bowel transplantation in children. Transplant Proc 1990; 22: 2499-500.

7 Goulet O, Révillon Y, Brousse N, Jan D, Canioni D, Rambaud C, et al. Successful small bowel transplantation in an infant. Transplantation 1992; 53: 940-3.

8 Springer TA. Traffic signals for lymphocyte recirculation and leukocyte emigration: the multistep paradigm. Cell 1994; 76: 301-14.

9 Cerf-Bensussan N, Schneeberger EE, Bhan AK. Immunohistologic and immunoelectronmicroscopic characterization of the mucosal lymphocytes of human small acterization of the mucosal lymphocytes of human small
intestine by the use of monoclonal antibodies. F Immunol intestine by the use of

10 Kutlu T, Brousse N, Rambaud C, Le Deist F, Schmitz J, Cerf-Bensussan N. Numbers of $T$ cell receptor (TCR) $\alpha \beta+$ but not of TCR $\gamma \delta+$ intraepithelial lymphocytes correlate with the grade of villous atrophy in coeliac patients on a long term normal diet. Gut 1993; 34: 208-14.

11 MacDonald TT, Ferguson A. Hypersensitivity reactions in the small intestine. Gut 1976; 17: 81-91.
12 Fromont G, Peuchmaur M, Devergne O, Jan D, Emilie D, Goulet $O$, Brousse $N$. In situ expression of cytokines and serine esterase $\mathrm{B}$ in small-bowel allograft rejection. Histopathology 1992; 22: 503-5.

13 Bishop JA, Hall B, Duggin G, Horwath J, Ross Scheil A, Tiller D. Immunopathology of renal allograft rejection. Analysis with monoclonal antibodies to mononuclear cell markers. Kidney Int 1986; 29: 708-17.

14 Azuma T, Sarnacki S, Révillon Y, Calise D, Goulet O, Brousse N, Cerf-Bensussan N. Study of graft infiltrating cells in a rejection model of small bowel transplantation in rats. Transplant Proc 1994; 26: 1523-4.

15 Kairserlian D, Rigal D, Abello J, Revillard JP. Expression, function and regulation of the intercellular adhesion molecule-1 (ICAM-1) on human intestinal cell lines. Eur f Immunol 1991; 21: 2415-21.

16 Kvale D, Krajci PK, Brantzaeg P. Expression and regulation of adhesion molecules ICAM1 (CD54) and LFA-3 (CD58) in human intestinal epithelial cell lines. Scand $\mathcal{F}$ Immunol 1992; 35: 669-76.

17 Ferran C, Peuchmaur M, Desruennes M, Ghoussoub J, Cabrol A, Brousse N, et al. Implications of de novo ELAM-1 and VCAM-1 expression in human cardiac allograft rejection. Transplantation 1993; 55: 605-9.

18 Brockmeyer C, Ulbrecht $M$, Schendel DJ, Weiss EH Hillebrandt G, Burkhardt K, et al. Distribution of cell adhesion molecules (ICAM-1, VCAM-1, ELAM-1) in renal tissue during allograft rejection. Transplantation 1993; 55: 610-5.

19 Malizia G, Calabrese A, Cottone M, Raimondo $M$, Trejdosiewicz LK, Smart CJ, et al. Expression of leukocyte adhesion molecules by mucosal mononuclear phagocytes in inflammatory bowel disease. Gastroenterology 1991; 100: 150-9.

20 Schuermann GM, Aber-Bishop AE, Facer P, Lee JC, Rampton DS, Doré CJ. Altered expression of cell adhesion molecules in uninvolved gut in inflammatory bowel disease. Clin Exp Med 1993; 94: 341-7.

21 Koizumi M, King N, Lobb R, Benjamin C, Podolsky DK. Expression of vascular adhesion molecules in inflammatory bowel disease. Gastroenterology 1992; 103: 840-7.

22 Lenshow DJ, Bluestone JA. T cell co-stimulation and in vivo tolerance. Curr Opin Immunol 1993; 5: 747-52.

23 Briskin MJ, McEvoy LM, Butcher EC. MadCAM-1 has homology to immunoglobulin and mucin-like adhesion receptors and to IgA1. Nature 1993; 363: 461-4.

24 Spencer J, Dillon SB, MacDonald TT, Isaacson PG. T cell subclasses in fetal human ileum. Clin Exp Immunol 1986; 65: 553-8.

25 Russell GJ, Bhan AK, Winter HS. The distribution of T and $B$ lymphocyte populations and MHC class II expression in human fetal and postnatal intestine. Pediatr Res 1990; 27: 239-44.

26 Guy-Grand D, Griscelli C, Vassalli P. The gut-associated lymphoid system: nature and properties of the large dividing cells. Eur F Immunol 1974; 4: 435-43.

27 Guy-Grand D, Cerf-Bensussan N, Malissen B, MalassisSeris M, Briottet C, Vassalli P. Two gut intraepithelial CD8 + lymphocyte populations with different $T$ cell receptors: a role for the gut epithelium in $\mathrm{T}$ cell differentiation. $₹$ Exp Med 1991; 173: 471-81.

28 Cerf-Bensussan N, Quaroni A, Kurnick JT, Bhan AK. Intraepithelial lymphocytes modulate Ia expression by Intraepithelial lymphocytes modulate Ia expression by

29 Bland PW, Warren LG. Antigen-presentation by epithelial cells of the rat small intestine. I. Kinetics, antigen specificity and blocking by anti-Ia antisera. Immunology 1986; 58: 1-7.

30 Bland PW, Warren LG. Antigen-presentation by epithelial cells of the rat small intestine. II. Selective induction of suppressor T cells. Immunology 1986; 58: 9-14.

31 Mayer LL, Schlien R. Evidence for function of Ia molecules on gut epithelial cells in man. $f$ Exp Med 1987; 166: 1471-83.

32 Kaiserlian D, Vidal K, Revillard JP. Murine enterocytes can present soluble antigen to specific class-II restricted present soluble antigen to specific class-11

33 Hoang P, Crotty B, Dalton HR, Jewell DP. Epithelial cells bearing class II molecules stimulate allogeneic human colonic intraepithelial lymphocytes. Gut 1992; 33: 1089-93

34 Xia W, Brandeis JM, Sayegh M, Kirkman RL. Mesenteric and intraepithelial lymphocytes are insufficient to cause rejection but able to mediate lethal graft versus host disease in small bowel transplants. Transplant Proc 1994; 26: 1508-9. 